\title{
DIVISION IV/V WORKING GROUP on ACTIVE B STARS
}

\author{
PRESIDENT \\ VICE-PRESIDENT \\ PAST PRESIDENT \\ MEMBERS
}

\author{
Geraldine J. Peters \\ Carol E. Jones, Richard D. Townsend \\ Juan Fabregat \\ Karen S. Bjorkman, M. Virginia McSwain, \\ Ronald E. Mennickent, Coralie Neiner, \\ Philippe Stee, Juan Fabregat (non-voting)
}

\section{PROCEEDINGS BUSINESS SESSIONS, 6 August 2009}

\section{Introduction}

The meeting of the Working Group on Active B Stars consisted of a business session followed by a scientific session containing nine talks. The titles of the talks and their presenters are listed below. We plan to publish a series of articles containing summaries of these talks in Issue No. 40 of the Be Star Newsletter $\uparrow$. This report contains an account of the announcements made during the business session, an update on a forthcoming IAU Symposium on active B stars, a report on the status of the Be Star Newsletter, the results of the 2009 election of the SOC for the Working Group for 2009-12, a listing of the Working Group bylaws that were recently adopted, and a list of the scientific talks that we presented at the meeting.

\section{Business session}

\subsection{Announcements}

1. A proposal to continue IAU recognition of the Working Group was submitted by G. Peters \& J. Fabregat by the 2009 February 28 deadline.

2. The triennium report for the WG for 2006-09 was prepared and submitted by J. Fabregat \& G. Peters by the 2008 July deadline. It was published in 2008 December in IAU Transactions XXVIIA and in Issue No. 40 of the Be Star Newsletter.

3. A proposal to hold a meeting on active B stars in Paris in the summer of 2010 was submitted by C. Neiner by the 2008 December 1 deadline. Our proposal entitled "Active OB stars: structure, evolution, mass loss, and critical limits" was accepted as one of the eight IAU Symposia to be held in 2010. It has been designated as IAU Symposium No. 272 and will take place from July 19-23.

\subsection{IAU Symposium No. 272}

C. Neiner, chair of the SOC for IAU S272 "Active OB stars: structure, evolution, mass loss, and critical limits" presented an update on the plans for the meeting. The venue for the meeting will be Eurosites-Rpublique, 8 bis, rue de la Fontaine au Roi, 75011 Paris. An overview of the scientific program, key dates, and social events can be found on the meeting's website http://iaus272.obspm.fr/.

$\dagger$ The official publication for the IAU Working Group on Active B Stars. 


\subsection{Be Star Newsletter}

The Be Star Newsletter, which is published in hard copy at Georgia State University for the Working Group on Active B Stars, continues to be the main source of information on new discoveries, ideas, manuscripts, and meetings on active B stars. G. Peters, D. Gies, and D. McDavid continue, respectively, as Editor-in-Chief, Technical Editor, and Webmaster. Abstracts and announcements are usually posted on our website (http://www.astro.virginia.edu/dam3ma/ benews/) within $48 \mathrm{hrs}$ of being received. Articles submitted for publication have been refereed since 2000 leading to an improvement in the quality of the Newsletter. When we have accumulated about 50 pages of material we finalize an issue and print hard copies that are mostly distributed to libraries worldwide. We encourage researchers to submit material to our Community Comments section that we introduced in 2005 to allow Working Group members to voice opinions or ideas on which the community can submit rebuttal, similar to unedited discussion that is sometime published as part of meeting proceedings. During the past triennium we have published Issues Number 38 (March 2007) and 39 (June 2009). The latter contains the proceedings from the scientific session held during the meeting of the Working Group on Active B Stars at the $26^{\text {th }}$ IAU General Assembly in Prague, Czech Republic.

\subsection{SOC Election Results}

The election to replace the four retiring members of the SOC was held in 2009 July. E-mail ballots were sent to all current IAU members of the Working Group on Active B Stars. The Scientific Organizing Committee (SOC) for the 2009-12 triennium is:

Term expiring in 2012: Karen Bjorkman, Coralie Neiner, Geraldine Peters, Philippe Stee Term expiring in 2015: Carol Jones, Virginia McSwain, Ronald Mennickent, Richard Townsend Non-voting: Christopher Corbally (President of IAU Division IV: Stars), Steven D. Kawaler (President of IAU Division V: Variable Stars), Juan FabregatOutgoing SOC Chair)

\subsection{Bylaws for the IAU Working Group on Active B Stars}

A key action item for the triennium 2006-09 was to establish a formal set of bylaws for the Working Group. These were finalized by the SOC prior to this businesses meeting and are presented verbatim below.

\section{Nature and Goals of the Working Group}

The Working Group on Active B Stars (formerly known as the Working Group on Be Stars) was re-established under IAU Commission No. 29 in 1979 at the 17th IAU General Assembly in Montreal, Canada, and has been in continuous operation to the present. Its main goal is to promote and stimulate research and international collaboration in the field of the active earlytype (OB) stars. The focus of the WG was originally on the classical Be stars, but in recent years there has been an increasing contact and overlap with other research areas, particularly in closely aligned topics such as pulsating OB stars and B stars in interacting binaries. The Working Group on Active B Stars is an IAU Inter-Divisional Working Group sponsored by Divisions IV (Stars) and V (Variable Stars).

Our goal is to investigate active phenomena in B-type stars including mass loss and accretion, pulsations, rotation, magnetic fields, and binarity and determine the fundamental parameters for these objects and to promote collaboration and interaction between scientists specializing in these studies.

\section{Membership}

Membership is open to any scientist working in the field of active B stars, including amateur scientists. IAU membership is required to run for a place on the Scientific Organizing Committee (SOC) and to serve on the SOC. Members receive e-mail updates on news items published in the Be Star Newsletter, the official publication for the Working Group. One can join the Working Group by contacting the webmaster of the Be Star Newsletter.

\section{Newsletter and Website}

The Be Star Newsletter is the official publication for the Working Group. The Newsletter is published irregularly with a frequency governed by the number of items submitted. News items, including announcements for meetings of interest to the Working Group and abstracts of 
new papers, and longer articles are submitted to the Editor-in-Chief. All articles are reviewed by anonymous referees who advise the Editor-in-Chief on the suitability for publication. All accepted articles are published on the official website for the Working Group soon after they have been accepted by the Editor-in-Chief. The website is maintained by a web editor. The technical editor is responsible for arranging for the printing and mailing of a paper copy of the Newsletter.

IV. Election of the Scientific Organizing Committee for the Working Group

The duties of the Scientific Organizing Committee (SOC) are to establish scientific policy of the Working Group, set up mechanisms to stimulate the collaboration between its members, and help to prepare proposals for scientific meetings of interest to the Working Group. Each member of the Working Group who is also an IAU member is permitted to nominate four persons as candidates for the new SOC and send them to the Election Officer. The Election Officer selects 10 candidates with the highest number of votes. If several individuals have the same number of nominations for the last spot on the ballot, they are all accepted and the number of candidates will be higher than 10 . According to the general IAU rules, only IAU members or new members pending approval at the forthcoming General Assembly can be accepted as candidates for SOC membership Geographically balanced representation should be taken into account in the nomination of the candidates. The Election Officer must verify that all nominees to be listed as candidates on the ballot are willing to serve if elected.

The four new SOC members are elected from the candidates by the members of the Working Group who are members of the IAU. Each IAU member may vote for up to four different persons. The four persons with the largest numbers of valid votes are elected. In the case of a tie, a runoff election will be held. The term of an SOC member lasts for a duration of six years, and begins at the conclusion of the IAU General Assembly in the year he/she is elected. A person must wait for six years, or two IAU General Assemblies, in order to run again for a position on the SOC. The four new and the four continuing SOC members determine among themselves the new Chairperson.

V. Ratification of the Bylaws

The bylaws are ratified by the SOC, and may be amended as per input from the Working Group membership. Ratification is by a simple majority, or a yes vote by at least $5 / 8$ SOC members. Amendments become valid at the conclusion of each IAU General Assembly

\section{Scientific program}

Session 1 (G. Peters, Chair)

09:30 CoRoT and the Be stars

J. Fabregat

10:00 Watching the growth of a disk: 37 days of H-alpha spectroscopy of HD 168797

E. Grundstrom

10:15 Influence of $X$-ray radiation on wind structure of hot stars

J. Krticka

10:30 Coffee

Session 2 (J. Fabregat, Chair)

16:00 Active B stars and the new class of gamma-ray binaries"?

V. McSwain

16:15 Magnetism in massive stars

G. Wade

16:45 On the incidence of magnetic fields in slowly-pulsating B, $\beta$ Cephei and B-type emission line stars

J. Silvester 
17:10 Non-radial pulsations in the open cluster NGC 3766

R. Roettenbacher

17:20 Analysis of B and Be star populations of the double cluster $h$ and chi Persei A. Marsh

Session Ends

\section{Closing remarks}

I would like to thank the speakers who presented a set of excellent talks and all who attended the Working Group meeting. Impressive new information on the nature of B stars and their activity is emerging that could barely be imagined three decades ago when this Working Group was re-established at the XVII IAU General Assembly in Montreal, Quebec. We heartedly thank outgoing SOC chair Juan Fabregat, for his skillful leadership and assistance in preparing the various reports and other documents that were submitted to the IAU General Secretary. We are looking forward to seeing you again in 2012 at the meeting of the Working Group on Active B Stars at the 28th IAU General Assembly in Beijing.

Geraldine J. Peters Chair of the Working Group, 2009-12 